\title{
PLATO AND ARISTOTLE ON FORM AND SUBSTANCE
}

\section{Introduction}

Plato and Aristotle give different answers to the question 'What are the substances (ousiai)?'. One way Aristotle defends his answer is by arguing that his candidate substances - particulars such as Socrates or Callias - better satisfy the criteria for substance than do Plato's candidates - eternal, unchanging, nonsensible universals called 'Forms'.' This defense goes along with another. For Aristotle disagrees with Plato, not only about the candidates, but also about the criteria, for substance: one reason Plato fastens on to the wrong candidates is that he focuses on some of the wrong criteria.

Aristotle mounts his defense in different ways in the Categories and Metaphysics. In both works he defends the priority of particulars. In the Cat., however, their nature is left unanalysed; and their priority is defended largely by appeal to unPlatonic criteria. In the Met., by contrast, Aristotle analyzes particulars into compound, form, and matter. Socrates, for example, may be viewed as a compound of his form (his soul) and his matter (his body); or he may be viewed as his form or soul. Further, Aristotle now invokes additional, Platonic criteria for substance; and this leads him to argue that it is Socrates as form that counts as primary substance; the primary substances are individual forms. ${ }^{2}$

By the time of the Met., then, Aristotle agrees with Plato that the primary substances are forms; but Platonic and Aristotelian forms are quite different. Platonic Forms are universals; Aristotelian forms are particulars; where there can be at most one Platonic Form corresponding to a given predicate, there may be several Aristotelian forms; and many Aristotelian forms, though no Platonic ones, are sensible, perishable, and changeable.

Why, and with what justification, does Aristotle prefer his candidates and criteria to Plato's? Is he right to believe that his candidates (ASs, for 'Aristotelian substances') fare better than do Platonic Forms (PFs)? And are his criteria plausible? I shall suggest that where Plato's and Aristotle's criteria converge, PFs if anything fare better than do ASs; Aristotle can defend his candidates only by significantly weakening his own criteria, a weakening Plato need not countenance. Where their criteria diverge, PFs fare badly; but this is not obviously to PFs' discredit, since such criteria are not plausible necessary conditions on substance. 


\section{Substance and Essence}

First we need a more detailed account of what substances (ousiai) are, and of Plato's and Aristotle's candidates for that role; so let me begin with that.

'Ousia' is a verbal noun from the Greek verb 'to be'. As Aristotle uses the word, it occurs in two distinct grammatical constructions. We can say that $\mathrm{x}$ is an ousia - a being, reality, or substance; or we can say that the ousia of $x$ is $F$, where ' $F$ ' answers the 'What is it?' question about $x$. In the first construction, we are talking about substances, full stop; in the second, about the substances of things - here 'ousia' carries a dependent genitive. ${ }^{3}$

On the first use, ousiai are the basic beings there are, whatever these turn out to be. To call something an ousia, in this sense, is to confer basicness; but there is no antecedent restriction on what sort of thing fills the bill. Let us call this sort of ousia. primary substance. Any entities one takes as basic or fundamental are one's primary substances. For the Presocratics, the primary substances are various sorts of material stuff - water or air or fire; for Plato, they are eternal, unchanging, nonsensible universals called 'Forms'; for Aristotle they are particulars such as Socrates or Callias.

In its second use, Aristotle often identifies a thing's ousia with its essence or nature (e.g. Met. 1017b21-21; 1031a18); so let us call this sort of ousia. essence. If you think everything is essentially watery, you think water is the ousia, essence, of things; if you think living a certain sort of life is the human essence, you think living that sort of life is the ousia of human beings.

It is natural, but not necessary, to identify these two sorts of ousiai - to believe, that is, that the essences of things are the primary substances. That, I take it, is Plato's view: his primary substances are his Forms; and he takes Forms to be the essences of things. We specify a thing's essence, say what it is, by suitably relating it to the relevant Form or Forms. It is, indeed, in part because he believes that Forms provide answers to the 'What is it?' question - are the essences of things - that he takes them to be the primary substances. ${ }^{4}$

In the Cat., by contrast, Aristotle resists the Platonic identification of primary substance and essence. There he argues that the primary substances are not universals of any sort, but such entities as an individual man or horse or tree. $\mathrm{He}$ does not say that such entities are primary substances because they are essences; indeed, they do not appear to be essences at all, although they have essences. Their essences are their species and genera - universals in the category of substance; and these are Aristotle's secondary substances. Hence, although no universal is a primary substance, Aristotle concedes to Plato that at least some universals - the species and genera of primary substances - are secondary substances. One reason they count as secondary substances is that they tell us what the primary substances are - that is, are their essence. ${ }^{5}$ A ristotle thus sees some connection between being a substance and being an essence. But what the primary substances are is not 
determined by appeal to essence; and essences are demoted to the status of (at best) secondary substances. ${ }^{6}$

In the Met., on the other hand, Aristotle is newly sympathetic to Plato's identification of primary substance, form, and essence. He now argues that each primary thing is identical to its essence (Z. 6), and that the form of each thing is its essence, and so is primary substance $(1032 \mathrm{bl}-2)$. This claim is liable to misinterpretation, however, so let me say a bit more about the Met.'s view of things before proceeding further.

In the Cat., some entities called 'eide्र ${ }^{7}$ - substance species - are allowed to be secondary substances and essences. When Aristotle, in the Met., argues that eide forms - are primary substances, is he arguing that the Cat.'s secondary substances (or their universal forms or essences) are primary substances after all - that, as for Plato, certain universals are the primary substances? So it is sometimes thought. G. E. L. Owen, for example, in 'The Platonism of Aristotle', writes that in Met. Z, Aristotle argues that: ${ }^{8}$

if we take any primary subject of discourse and say just what it is, we must be producing a statement of identity, an equation which defines the subject. And this in turn helps to persuade him that the primary subjects of discourse cannot be individuals such as Socrates, who cannot be defined, but species such as men. In the Categories, on the other hand, the primary subjects are still the individual man or horse or tree. Aristotle seems at this early stage to be much more hostile than he later becomes to Plato's treatment of the species as a basic and independent subject of discourse. So it becomes tempting to think of this element in Metaphysics VII as a return to, or a renewal of sympathy with, Plato.

But I believe that the eidé that now count as primary substances are not species, or universals of any sort, but individual forms; it is, e.g., Socrates' individual form or essence, his soul, that now counts as a primary substance. This goes beyond the Cat., insofar as the Cat. does not analyse particulars; it does not invoke the notions of compound, form, and matter, nor argue that individual forms are the primary substances. But Aristotle still maintains the Cat.'s view that particulars are the primary substances. Hence, when he suggests that Socrates is identical with his form, he does not, as is sometimes said, ${ }^{9}$ mean that he is identical with the species man (or to the universal form of that species), but that he is identical with his soul, which is proprietary to him. Aristotle's promotion of form and essence, then, is not a concession to Plato about the priority of universals; there is no 'renewal of sympathy with' Plato on this score. Indeed, the Met. is, if anything, more hostile to universals than is the Cat.; for it revokes the Cat.'s concession that at least some universals are secondary substances. In the Met., no universal is a substance at all (see esp. Z. 13 at, e.g., 1038b8-16, b34-1039a2). though Plato is right to identify primary substance, form and essence, he proposes the wrong candidates for playing 
these roles.

The claim that the primary substances of the $\mathbf{M e t}$. are individual forms is, to say the least, highly controversial, and I shall not mount anything like a complete defense of it here. But in the next section I argue that Aristotle's criteria for substance require that all substances be particulars; and in subsequent sections I argue that Aristotle can escape his criticisms of Plato only if his substances are particulars. Aristotle may, of course, be inconsistent, and other evidence might pull us in a different direction. But if we focus on his criteria for substance, and on his criticism of Plato, we are pulled towards individual forms. To defend individual forms is not, however, the main purpose of this paper; the main purpose is to assess the plausibility of Aristotle's criticisms of the claim of PFs to substancehood, and his success in defending his alternative. The first stage in such an analysis must be consideration of Aristotle's criteria for substance, so I turn next to that.

\section{Criteria for Substance}

Although criteria can be culled from many sources, I shall focus on criteria Aristotle commends in the Cat. and $\mathbf{M e t}$.

(1) Substances persist through change. In the Cat. Aristotle proposes the following idion - special feature or distinguishing mark - of substance: 'It seems most distinctive of substance that what is numerically one and the same is able to receive contraries. In no other case could one bring forward anything, numerically one, which is able to receive contraries' (4a10-13). Although (1) is proposed as distinctive of substance, strictly speaking it is distinctive only of primary substance. Aristotle is concerned, not with the fact that, for example, the species man can be pale and dark - that there can be pale and dark men - but with the fact that an individual man can be pale at one time, dark at another. (1) thus requires of (primary) substance that it be able to sustain change through time; (primary) substances are the basic subjects of change. 10

(1) is necessary and sufficient for being a primary substance. But it is not necessary for being a substance, since there are secondary substances, and they do not satisfy (1) (except, of course, insofar as their members do).

(2) Substances are (basic) subjects. In the Cat., something is a subject just in case something can be predicated of it; and something is a basic subject just in case it is a token of a type such that tokens of that type are not predicated of anything, but all other sorts of things are ultimately predicated of tokens of that type. In the Met., by contrast, Aristotle explicates the notion of a subject (and not just of a basic subject) in terms reminiscent of the Cat.'s notion of a basic subject. In Z.3 for example, he says that a subject is "that of which other things are predicated, while it itself is no longer <predicated> of anything' $\left(1028 \mathrm{~b} 36-7\right.$; but cf. $\Delta .8,1017 \mathrm{~b} 23-4$, $\tau$ ó $\theta^{\prime}$

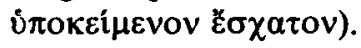

In the Cat., being a subject is necessary but not sufficient for being a substance; 
and being a basic subject is both necessary and sufficient for being a primary substance (2al1-14; a34-5; b36-3a1). Correspondingly, in the Cat., particulars such as Callias count as basic subjects; but one reason secondary substances are adjudged substances is that they are the next best subjects - they are secondary subjects (2b15-22; b36-3a6).

In the Met., by contrast, being a subject (that is, being one of the Cat.'s basic subjects) is apparently both necessary and sufficient for being a substance tout court $(1029 \mathrm{a} 1-2 ; 17-19 ; 1038 \mathrm{~b} 15)$. Since every universal is, in Aristotle's view, necessarily predicated of something (e.g., 1038b15-16), no universal (and so no secondary substance) is a subject. (2) thus requires that the Met.'s substances all be particulars.

(3) Substances are thises (tode ti). In the Cat. (3b10-18), Aristotle takes it to be both necessary and sufficient for being a this that something be a particular. Thus he first claims that whatever is indivisible and one in number - that is, is a particular - is a this (3b10-13); he then argues that secondary substances are not thises, because they are said of many things (3b13-18) - that is, are universals. This leaves open the possibility that nonsubstance particulars are thises, and so the $\mathrm{Cat}$. seems to allow. In the Cat., then, being a this - that is, a particular - is necessary but not sufficient for being a primary substance; but it is neither necessary nor sufficient for being a substance.

In the Met., the status, explication, and application of the thisness criterion change. First, it is now necessary and sufficient for being a substance; ${ }^{11}$ in contrast to the Cat., there are no longer any nonsubstance thises. Second, thisness is no longer explicated in terms of particularity. In truth, Aristotle never provides a clear explanation of the notion; but it seems to convey the idea of determinateness, perhaps of countability, and of being a stable object of reference. And at 1030a4, he suggests that a this must not essentially involve one thing's being said of another. Third, although thisness is no longer explicated in terms of particularity, it still applies only to particulars - though not to all particulars, at least not in the primary way. Now every universal, in Aristotle's view, is necessarily said of something; hence none is a this $(1038 \mathrm{~b} 15-16 ; \mathrm{b} 35-1039 \mathrm{a} 2)$. If no universal is a this, but every substance must be, then, once again, it follows that Aristotle's substances in the Met. are all particulars.

Aristotle uses the notion of thisness, not only to exclude universals from the ranks of substance, but also to restrict the range of particulars that so count. In Z.4, for example, he argues that a white man is not a this, since it essentially involves one thing's being said of another - white of the man. Aristotle also seems to believe (a point which perhaps emerges most clearly in Z.11) that a man considered as a compound is not a this, since his form is essentially said of his matter. It is individual forms that count as thises in the primary way, and so they are the primary substances. 
(1-3) are all present in the Cat.; and at least (2-3) are present in the Met. as well, though they are there handled differently and used to different ends. ${ }^{12}$ In particular, they are all used to show that all substances are particulars. The Met. also highlights further criteria, either absent or muted in the Cat.:

(4) Substances are separate (choris, choriston). ${ }^{13}$ In Met. Z. 1, Aristotle says that substances are naturally prior to nonsubstances, because only they are separate (1028a33-4). ${ }^{14}$ 'Separate' is not explained here; but in $\Delta .11$, Aristotle says that substances are naturally prior to other things because they 'can be without the other things, while the others cannot be without them' $(1019 \mathrm{a} 1-4)$. A is separate from $B$, then, just in case $A$ can exist without B. Aristotle believes that substances are separate from other things, though not conversely. Like (2-3), (4) appears to be a necessary and sufficient condition for substance in the $\mathrm{Met}$. Since only substance is separate, it is sufficient; and since all substances must be separate, it is necessary.

In both the Cat. (2b3-6) and Met. (e.g. 1086b3-5), Aristotle denies that universals (and so the Cat.'s secondary substances) are separate. ${ }^{15}$ In the Cat., the species and genera of substance, though not separate, are nonetheless allowed to be secondary substances. In the $\mathrm{Met}$, , however, the fact that universals are not separate debars them from the ranks of substance altogether. Once again, then, the substances of the Met. must all be particulars.

Notice that although the Cat. denies that universals are separate, it does not say that (primary) substance is separate. In contrast to the $M e t$., the $C a t$. contents itself with the weaker claim that everything else is dependent on the primary substances; but this leaves open the possibility that primary substances are similarly dependent on, and so are not separate from, other things. In the Met., the separation of substance is stressed, and used against universals.

(5) Substances are prior in definition. In Z.1, Aristotle says that substances are prior in definition because in the definition of each thing there must be a definition of the ousia' (1028a35-6). The force of (5) might be:

(5a) For all $x$, to define $x$, one must define its essence. Or it might be:

(5b) For all $x$, to define $x$, one must include a definition of a relevant substance.

Aristotle believes that definitions state essences (e.g., 1017b21-2; 1036a6-7); so he believes (5a). But (5) is a criterion for substance only if read as (5b). These two readings are connected, however, since Aristotle argues that to state the essence of anything, one must state the definition of (or at least mention) a relevant substance; hence (5a) implies (5b). Aristotle also argues (in Z.4) that the primary substances are the primary definables; and that the primary definables are identical to their essences (Z.6). Hence the essences mentioned in (5a) will be identical to the substances mentioned in (5b), in the case where $x$ is a primary substance. Notice that one result of this is that primary substances are essences.

Commitment to (5) is at best muted in the Cat.; but insofar as it is present, it appears to favor secondary over primary substances. For one reason secondary 
substances are adjudged substances is that they answer the 'What is it?' question about primary substances - they tell us what they are, are their essences (2b7-14; 2b29-37). (Some) definitions state, or are of, secondary substances; though the content of such definitions applies to, or is true of, primary substances, primary substances are not themselves definable nor, though they have essences (their secondary substances), are they themselves essences.

In the Met., by contrast, (5) is explicit; and it too now appears to be necessary and sufficient for substance. ${ }^{16}$ Now if, in the Met. as in the Cat., (5) favors universals, then Aristotle is in difficulty. For as the discussion in (2-4) reveals, Aristotle now denies that there are any universal substances; yet (5) is supposed to determine substance. To be consistent, then, he must argue that (5) determines particular substances.

(6) Substances are prior in knowledge. In Z.1, Aristotle argues that substances are prior in knowledge because "we think we especially know each thing when we know what it is - what man or fire is - rather than when we know $<$ what $>$ quality or quantity or where $<$ it is $>$; since we also know each of these $<$ only $>$ when we know what the quantity or quality is' (1028a36-b2).

Aristotle does not explicitly use 'ousia' in stating (6); and his use of ' $t$ i estin' suggests he is making a point analogous to (5a): to know something is to know what it is, that is, its essence. This point is relevant to the epistemological priority of substance, however, since Aristotle argues that to know the essence of anything, one must know a relevant substance. For to know something is to know its definition; and we saw, in discussing (5), that an adequate definition of anything must include a definition of a substance. Hence to know anything, one must know a definition of a substance. This again suggests that primary substances are essences. For presumably the primary knowables are the primary definables; and the primary definables, as we have seen, are essences.

In the Cat., commitment to (6) is muted; but insofar as it is present, it, like (5), appears to favor secondary over primary substances. In the Met., by contrast, (6), like each of (2-5), is a necessary and sufficient condition for substance; and, again, since universals no longer count as substances, Aristotle must, to avoid contradiction, show how particular substances satisfy it.

Our survey of criteria has brought to light some interesting differences between the Cat. and Met. The Cat. uses fewer criteria, at least explicitly; and different criteria enjoy different statuses-some are necessary but not sufficient for being a primary substance, some are necessary and sufficient, and so on. Further, different criteria favor different candidates: $(1-3)$ favor certain particulars as the primary substances; (5-6) (insofar as they are present) favor certain universals as secondary substances - though the favor is not so great as to challenge the primacy of 
particulars. (4) is not used at all.

In the Met., by contrast, each of (2-6) (where some of these are now explained differently) is apparently both necessary and sufficient for being a substance tout court. Moreover, all substances are now particulars; there are no longer any universal substances.

Contrary to Owen and others, then, the Met. does not display increased sympathy with Plato on the status of universals; it is if anything more hostile to them. For it revokes the Cat.'s concession that at least some universals count as secondary substances; the criteria for substance debar all universals from the ranks of substance.

In other respects, however, the Met. is more sympathetic to Plato. For the particulars that now count as primary substances are individual forms; Aristotle, like Plato, now promotes forms and essences (though non-Platonic ones) as primary substances. Further, his use of criteria owes something to Plato too. (1-3), the criteria highlighted in the Cat., are unPlatonic; in the Cat., Aristotle fights Plato on foreign territory. But (4-6) are Platonic criteria (or so at least Aristotle believes): the battle now moves to home turf; the $M e t$. engages in a dialectical debate absent in the Cat. But although this in a way displays increased sympathy with Plato, in a way it does not. For Aristotle argues that even if we give Plato his criteria, PFs do not qualify as substances. Let us see how well he prosecutes his case.

\section{Platonic Substances}

(1) Since PFs cannot sustain change through time, they obviously fail (1)-just as do the Cat.'s secondary substances. But I doubt that Plato would be much worried; he would challenge the criterion. To be sure, he might argue, it might be reasonable to insist that the basic entities in the universe be stable, persist from one moment to the next. But of course PFs are stable, indeed, eminently so. If (1) is weakened to stability, it is plausible; but then PFs satisfy it. If it is strengthened in Aristotle's way, it is not plausible.

Aristotle might reply that stability is not enough; the stable entities must explain changes objects in the world undergo - yet PFs cannot explain change (991a 8-11; $991 \mathrm{~b})$. Now it might be reasonable to require explanatory relevance to change; but I think Plato could fairly insist that PFs are explanatorily relevant to change. To be sure, they do not initiate change; they are not efficient causes of change. ${ }^{17}$ But as Aristotle should be the first to agree, efficient causes are only one sort of explanation of change. Not would Aristotle be reasonable to require that whatever explains change must itself change; indeed, his own prime mover explains at least some changes but does not itself change. PFs, being properties, are relevant indeed necessary - to explaining some changes, even though they themselves do not change; for explanations of change require reference to the properties involved; and PFs are among the properties there are. 
Aristotle may be right, then, to require that substances be stable and explanatorily relevant to change; if (1) is so weakened, it is at least a reasonable necessary condition on substance - but one PFs satisfy. If, however, it is strengthened so as to require that substances be capable of sustaining change through time, then it is not a reasonable necessary condition on substance, and so PFs' failure to satisfy it is not to their discredit.

Aristotle might, however, fairly protest (though Plato would no doubt reject the protest) that (1) is a reasonable sufficient condition for substance - for it seems reasonable to assume that among the entities explanatorily relevant to change are those that undergo and sustain change. PFs' failure to satisfy a sufficient condition for substance does not show that they are not substances at all; but if other entities than PFs satisfy (1), that would show that PFs are not the only substances.

(2) Just as Aristotle denies that PFs satisfy (1), so he denies they satisfy (2); PFs are not basic subjects. Indeed, in the $\mathbf{M e t}$. they are not subjects at all.

Plato would probably agree that PFs are not basic subjects; in the Timaeus he seems to accord the receptacle that role (see, e.g., 49e7ff; 50b5ff). But Plato would again simply reject the criterion. To be sure, he might argue, it might be reasonable to insist that the basic entities be subjects in the following sense: 'those subjects of discourse to which all our descriptions of the world must, at any rate when properly analysed in canonical form, make direct or indirect reference'. ${ }^{18}$ But PFs are basic subjects in this weakened sense; for to call something a basic subject in this sense is only to call it a fundamental explanatory entity. It is only by tightening (2) up and restricting it to (basic) subjects of properties, that Aristotle can use it against Plato; but since (2) so construed is an implausible criterion for substance, this does not harm Plato.

I think Plato would be right to protest against (2), construed as a necessary condition on substance. What, after all, makes subjects prior to their properties? Perhaps Aristotle would say, appealing back to (1): the fact that subjects can sustain change of property through time. But even if this is so, I have suggested that properties are equally necessary to explaining change - we should not be forced to choose between them. Or perhaps Aristotle would say that subjects are favored over properties because properties depend on, cannot exist without, their subjects. But it is far from clear that properties are dependent on their subjects; perhaps they can exist uninstantiated. ${ }^{19}$ It is difficult to see, however, how subjects can exist without properties; do not properties then have the edge? Or are not properties and their subjects at least mutually dependent? (See further, IV (4) and V (4).) Or perhaps Aristotle would say that we invoke properties to explain particulars, and that explananda are prior to explanantia. But why are not explanantia at least as basic or fundamental as explananda?

(2), then, is not a plausible necessary condition on substance. but Aristotle might with more reason defend its sufficiency - for subjects, no less than their properties, seem necessary to explaining change; explananda seem as fundamental as 
explanantia. And although this would not dislodge PFs as substances, it would show, if other things satisfy (2), that PFs are not the only substances.

(3) In contrast to (1-2), Aristotle seems to believe that PFs satisfy (3). At least, he insists that Plato treats PFs as thises (S.E. 22; Met.Z.13). This might be thought an advantage of PFs; but in Aristotle's view, it is not. He argues that because PFs are thises, they are vulnerable to the TMA - a vicious infinite regress. Though PFs satisfy (3), this leads to severe difficulties; satisfaction of (3) is thus no boon.

Aristotle in effect levels a dilemma against Plato: either (a) PFs are thises, and so are vulnerable to the TMA; or else $(b)$ they are not thises, and so cannot be substances. On the face of it, this is an odd criticism for Aristotle to press. For (3) is an Aristotelian criterion. If PFs are vulnerable to this dilemma, how can Aristotle escape it?

The answer, in brief, is as follows: PFs are not vulnerable to the TMA merely because they are thises, but because (so Aristotle believes) they are also universals; it is because they are allegedly universals and particulars at once that the TMA threatens. Aristotle can avoid the dilemma, then, if ASs are thises but not also universals. Here is one reason to doubt that ASs are universals of any sort - for if they were, they would succumb to Aristotle's dilemma. ${ }^{20}$

Whether or not Aristotle can escape his dilemma, I believe Plato can: he would protest against both $(a)$ and $(b)$. As to $(a)$ : if we think of the Cat.'s account of thisness, in terms of particularity, then I doubt that PFs are thises; they are universals but not particulars.

Why does Aristotle disagree? Later (in IV (4)) I shall sketch an argument of Aristotle according to which the separation of PFs implies their particularity; but this argument fails. Of course, even if separation does not imply particularity, PFs might nonetheless be particulars. Some (perhaps including Aristotle) believe that self-predication has this result; but this is unclear. First it is unclear that Plato even accepts self-predication, as that notion is traditionally construed. ${ }^{21}$ But second, even if he does, it does not, in general at least, imply particularity. The Form or property or universal of immobility, e.g., can be immobile without thereby being a particular; all universals are immobile, but they are not thereby all particulars. It is not clear, then, that PFs are particulars, and so not clear that they are thises, as the Cat. conceives them.

If we turn, on the other hand, to the Met.'s account of thisness, in terms of one thing's not being essentially predicated of another, and determinacy, then I think Plato would say that PFs are thises, and so satisfy (3): for since they can exist uninstantiated, they are not what they are in virtue of being said of anything; and they can also be stably referred to. ${ }^{22}$ But this does not, pace Aristotle, turn them into particulars; not only particulars satisfy (3), understood in the Met.'s way. Since I am sympathetic to the possibility of uninstantiated universals, this reply seems reasonable to me.

Either, then, PFs fail (3), construed in terms of particularity; or else they satisfy 
it, construed in the Met.'s way, but do so without thereby becoming particulars. If PFs are not thises, are they not vulnerable to $(b)$ ? Here I think Plato would follow a by now familiar ploy: (3), construed in terms of particularity, is not a plausible criterion for substance, and so PFs' failure at (3), so construed, does not impugn their status as substances. And since even Aristotle does not believe that (3), so construed, is a sufficient condition for substance, the fact that other sorts of entities than PFs satisfy (3) would not even lead us to question PFs' status as the substances.

If, on the other hand (3) is instead construed in the Met.'s way, then, as Aristotle believes, it may well be at least a plausible necessary condition for substance; for we expect substances to be determinate, stable objects of reference. But as we have seen, PFs (despite Aristotle's view to the contrary) satisfy (3) so construed.

PFs fail (3), then, only if it is implausible; they satisfy (3) on its more plausible reading - but they do so without being particulars, or succumbing to the TMA.

(4) Just as Aristotle insists that PFs are thises, so he insists they are separate (see, e.g., 1078b30-31; 1086a32-b13); and he appears to be correct. At least, in the Timaeus, Plato seems committed to the separation of at least some PFs. For there he commits himself to the following two claims:

(a) Forms have always existed.

(b) Sensibles have not always existed.

(a) and (b) imply:

(c) There was a time at which Forms, but no sensibles, existed.

And $(c)$ implies that at least some Forms are separate. For if, as $(c)$ says, there was a time when some Forms, but no sensibles, existed, and if separation is just the capacity for independent existence, then obviously at least some PFs are separate. Here, then is one criterion for substance Aristotle correctly says PFs satisfy.

Although Aristotle is correct to say that Plato is committed to the separation of some PFs, he is wrong to suggest, as he seems to,that (4) is a Platonic criterion for substance, a criterion Plato argues his PFs satisfy. It is in fact surprisingly difficult to find any commitment to separation in the dialogues; the issue is never explicitly broached, and Plato certainly never offers (4) as a criterion for substance. Aristotle could thus have prosecuted his dialectical case against Plato quite fairly without invoking (4); and in view of the difficulties he himself has with (4)(see V(4) below), this would have been to his advantage.

Although Aristotle concedes that PFs satisfy (4), he argues that their satisfaction of it is not to their credit, since severe difficulties then ensue. For if PFs are separate, they are thises, and so particulars; but since they are also universals, they are incoherent entities - both universals and particulars at once. ${ }^{23}$ This charge, however, fails; for the separation of PFs does not imply their particularity. (Notice, however, that since Aristotle believes that separation implies particularity, and since he insists that his substances are separate, he presumably believes that his substances are particulars.) If separation is just the capacity for independent 
existence; and if PFs are universals; then to say that they are separate is just to say that they can exist uninstantiated; and this does not turn them into particulars.

Why does Aristotle disagree? I can think of only one explanation. In De Int. 7, Aristotle defines universals as follows: 'by universal I mean that which by its nature is predicated of many things' (17a39-40). One might suppose he means only that universals can be predicated of many things; but he seems to mean instead that they must actually be predicated of many things. If, then, one countenances the possibility of uninstantiated universals, one countenances the possibility of something that can exist that is not actually predicated of many things. This cannot, by definition, be a universal; what else can it be, then, but a particular? Hence allegedly separate universals must actually be particulars.

This is not, however, so much an argument against separate universals as a definitional fiat that they cannot exist. Unless Aristotle can provide plausible reasons for his definition - and I cannot find any - his argument simply begs the question against the Platonist. And since I am myself sympathetic to the possibilty of uninstantiated universals, I am inclined to believe that PFs can be separate, while still retaining their status as universals. I conclude, then, that PFs nonproblematically satisfy (4).

(5-6) I believe Plato would argue that PFs satisfy (5-6). In the Meno, he argues that knowledge is true belief plus an explanatory account (an aitias logismos) (98a). In Phaedo 100, he argues that PFs are aitiai, basic causes or explanatory entities. Hence, adequate accounts must refer to PFs; all definitions, and so all knowledge (since knowledge requires definitions, logoi), involves reference to PFs. Similarly, in Rep. 5, Plato argues that knowledge involves appropriate reference to PFs. To know or define PFs, however, one need not - indeed, one cannot - first know or define other things; knowledge and definition of PFs is a precondition for knowledge and definition of anything. Hence, PFs are prior in knowledge and definition.

Further, Plato presumably believes that PFs are thus prior because he accepts the connection between knowledge, definition, and essence; it is because he believes that PFs are the essences of things, and that knowledge and definitions are of essences, that he believes that PFs are prior in knowledge and definition. Hence, for Plato as for Aristotle, constraints on knowledge and definition suggest that the primary substances are essences.

We have seen that Aristotle allows that PFs satisfy (4); does he also believe they satisfy (5-6)? Since he reject the existence of PFs, he of course does not believe they are really thus prior; still, does he believe Plato has a plausible case here?

One might believe he should. First, he agrees that PFs are at least universals; and he sometimes says that universals are prior in definition - perhaps, more strongly, that they are the only objects of knowledge and definition (see, e.g., Met. 1018 b32-3; Z.15; An.Po. passim). Second, he agrees that PFs are at least intended to be the essences of things (e.g. Met. $991 \mathrm{bl}-3=1079 \mathrm{~b} 35-1080 \mathrm{a} 2$ ); and so again he 
should concede that they are plausibly said to be prior in knowledge and definition.

Aristotle sometimes seems to suggest that at least Plato would reason in this way. In Met. A. 6, M. 4 and 9, for example, he suggests that Plato introduced PFs as stable objects of knowledge and definition; the possibility of knowledge and definition requires the existence of unchanging, nonsensible universals that the Platonists call 'Forms'. And in H.1, he says that PFs are thought to be substances for the same reasons that universals and genera are (1042a15-16) - presumably because they are all thought to be the essences of things, and so basic objects of knowledge and definition.

But Aristotle protests that this line of thought is implausible; he argues that, to the contrary, PFs are unknowable and indefinable. If so, they are not prior in knowledge and definition. Thus, in Met. Z.15, he argues that definitions are of universals and so PFs, being particulars, cannot be defined. In M.10, a parallel point is pressed for knowledge: since knowledge is of universals, and PFs are particulars, PFs are unknowable.

We have already seen why Aristotle believes PFs are particulars: because they are separate, and separation, Aristotle believes, implies particularity. Aristotle thus in effect now levels the following dilemma against Plato: (a) If PFs satisfy all of (4-6), they are incoherent entities, both universals and particulars at once - for satisfaction of (4) requires particularity, whereas satisfaction of (5-6) requires universality; (b) If PFs satisfy only (4) (and so are particulars), or only (5-6) (and so are universals), they fail to satisfy at least one necessary condition for substance. Either way, PFs cannot be the primary substances.

Once again, it is puzzling to see Aristotle levelling this dilemma. For (4-6) are not just criteria Plato, perhaps confusedly, commends; they are Aristotle's own criteria. If Plato is vulnerable to this dilemma, is not Aristotle vulnerable to it as well? Later we shall need to ask whether Aristotle escapes this dilemma and, if so, if he does so in a way that leaves intact his criticism of Plato.

For now it is worth noting that Plato has an easy escape route: he would simply reject (a). Separation does not imply particularity; hence PFs can satisfy all of (4-6), without incoherence, as universals. Since Aristotle believes that separation implies particularity, however, the same escape route is not open to him.

Aristotle might argue that even if all of this is so, there is another way in which the separation of PFs is incompatible with their being prior in knowledge and definition. If PFs are separate from sensible particulars, they cannot be their essences; and if they are not their essences, they are 'no help towards knowledge of them' (Met. 991 a 12-13=1079b 15-16). Even if PFs can be known, then, such knowledge would be useless; and so, again, they are not prior in knowledge and definition.

Thus in Met. Z.6 Aristotle argues that the essence of a primary thing is identical to that thing; if PFs are separate from sensible particulars, they cannot be identical to them and so, if sensible particulars are primary things, PFs cannot be their 
essences. Further, in Z.13 Aristotle insists that the essence of $x$ must be peculiar to $\mathrm{x}$; but the PF of man, e.g. (if there is one), is not peculiar to Socrates and so cannot be his essence. (Notice that these arguments again pull us in the direction of individual forms. At least, if Socrates has an essence at all (and he seems to), his essence must be peculiar to him; since no universal is peculiar to any particular, his essence must be a particular. But since essences are forms, there are individual forms; and they must be Aristotle's primary substances.)

Neither of these arguments depends on the dubious claim that separation implies particularity; and both strike me as more promising. Nonetheless, Plato is not without his resources. To the argument in Z.6, he would no doubt reply that sensible things are not primary things, and so need not be identical to their essences. On the other hand, PFs are primary things, and they are identical to their essences. Either way, Plato can accept the claim in Z.6 - that primary things are identical to their essences - without abandoning the claim that PFs are the essences of sensibles.

The argument of $Z .13$ is in effect an argument for individual essences; whereas Plato, in putting forth PFs as the essences of things, opts for general or universal essences - as had Aristotle in the Cat. Since I do not know whether there are individual essences, I do not know who has the better position here; certainly both views have serious philosophical credentials. But even if Aristotle is right on this score, it shows only that PFs cannot be the whole essence of any sensible; it does not show that they cannot be part of their essence, ${ }^{24}$ or that they are not knowable or definable. Indeed, unless we agree with Aristotle about the primacy of particulars, it does not even show that PFs are not prior in knowledge and definition.

If we accept the view Aristotle himself often advocates - that universals are prior in knowledge and definition - and agree, against Aristotle, that PFs are universals but not particulars, then PFs fare quite well on (5-6). The most Aristotle can persuade us of is that PFs cannot be the whole essence of any sensible; but that falls short of showing failure at (5-6).

To summarize so far: Aristotle is correct to say that PFs fail (1-2); but this does not impugn their status as substances, since (1-2) are not plausible necessary conditions on substance. The most Aristotle can fairly argue is that (1-2) are plausible sufficient conditions, so that if other things satisfy them, PFs are not the only substances. Aristotle is probably wrong, on the other hand, to argue that PFs satisfy (3) (if, that is, (3) involves particularity); but this does not even disqualify them as the substances, since (3) so construed is not, even by Aristotle's lights, a necessary or sufficient condition on substance. PFs do, however, satisfy (3) construed in the Met.'s way.

Aristotle believes PFs satisfy (3) because he believes they satisfy (4). They do satisfy (4); but this does not turn them into particulars - PFs can satisfy (4) as universals. Aristotle argues that PFs fail (5-6), again largely on the grounds that they are particulars; this argument fails, since PFs are universals, not particulars and Aristotle himself (sometimes) believes universals satisfy (5-6). Perhaps PFs are 
inadequate as the whole essence of particulars; but this is insufficient to show failure at (5-6).

PFs, then, fail the unPlatonic criteria (1-3) - the only criteria pressed in the Cat.; but this does not disqualify them as substances. On the other hand, they fare quite well on the allegedly Platonic criteria (4-6) highlighted in the Met. Though the dialectical project of the Met. is more impressive than is the quick attack in the Cat., it too fails to dislodge PFs from the ranks of substance.

Aristotle's offensive attack thus fails: he has not succeeded in persuading us that PFs are not substances. But a defensive strategy might still be successful: for perhaps Aristotle can persuade us that even if PFs are substances, they are not the only substances. And this might be accomplished in a variety of ways. If, for example, (1-2) are plausible sufficient conditions on substance, and if ASs satisfy them, this should persuade us to add ASs to the list of substances. Or if ASs do at least as well on (4-6) as PFs do, that too should persuade us to accept ASs along with PFs-if, that is, (4-6) are plausible criteria for substance.

\section{Aristotelian Substances}

(1) Aristotle is surely correct to say that the Cat.'s primary substances can persist while changing; ${ }^{25}$ and since PFs do not satisfy (1), ASs fare better here. Since (1) is only plausible construed as a sufficient condition this should not lead us to prefer ASs to PFs; but it does give us some reason to add ASs to the list of substances.

It is worth noting, however, that although the Cat.'s primary substances fare better on (1) than PFs do, various difficulties nonetheless arise. For example, Aristotle claims that only his primary substances satisfy (1). Yet by the time of the Physics, he acknowledges that matter appears to satisfy it as well - a lump of bronze, e.g., can sustain the change of shape that results in its constituting a ring. Perhaps this is one reason why (1) is muted in the Met.

(2) To be a (basic) subject, recall, is to be a token of a type none of whose members is predicated of anything, and is such that all other sorts of things are predicated of tokens of that type. We have seen that PFs (in common with all universals) fail (2). But, again, this is not to their discredit, since (2) is not a plausible necessary condition on substance. Still, we have agreed that (2) is a plausible sufficient condition on substance; if Aristotle's substances satisfy it (in which case they must be particulars), then once again we have reason to add them to the list of substances.

In the Cat., Aristotle claims that his primary substances are basic subjects; everything else is predicated of (said of or in) them, and they are not predicated of (said of or in) anything. But unlike Met., the Cat. does not wrestle with the notions of form and matter; and in the Met., where Aristotle wishes to promote individual form as primary substance, it appears that forms are predicated of matter. How, then, can they satisfy (2)? Indeed, it looks as though matter (or prime matter) is the 
only subject. For only matter is not predicated of anything; and everything else is ultimately predicated of it $(Z .3,1029 \mathrm{a} 7-27)$. (2) thus threatens to dislodge not only PFs, but also Aristotle's favored candidates. (Notice, though, that the threat is from matter, not universals.) Plato is unmoved; he rejects the criterion, perhaps because of the difficulties just adverted to. But Aristotle retains the criterion; so he needs to confront the difficulties.

And of course he does. He attempts to resist the descent to matter by arguing that, for example, matter does not do so well on other criteria for substance, such as separation and thisness $(\mathrm{Z} .3,1029 \mathrm{a} 27-30)$. This is not to the present point, however, which is that Aristotle's alleged primary substances do not do as well as he would like on the subject criterion.

A better argument is this one: that the way in which form is predicated of matter is importantly different from the way in which other things are predicated of form. To be a (basic) subject is to be a token of a type (i) none of whose members is predicated of anything but matter; and (ii) such that all other sorts of things than matter are predicated of tokens of that type.

This may allow individual forms to be (basic) subjects. But it does so by modifying the criterion. That might look like cheating - altering the criterion so that it picks out the desired candidates. But it is not cheating if Aristotle can produce a good argument to show that his modified subject criterion is preferable to the initial one - preferable, that is, not just because it yields the candidates he would like, but for reasons of general appeal. Perhaps Aristotle means to signal that this is his justification for the revision when he remarks $(\mathrm{Z} .3,1029 \mathrm{a9}-10)$ that the initial criterion is inadequate and unclear. Whether or not Aristotle has a good argument here is, of course, another question, and not one I shall try to answer here. Here the main point is that, although PFs fail (2), so too may Aristotle's favored candidates; but however well ASs fare here, this does not give us a reason to prefer them to PFs, since the criterion is not a plausible necessary condition on substance. Insofar as ASs satisfy (2), however, and insofar as it is a plausible sufficient condition, that gives us reason to believe that ASs, as well as PFs, are among the substances.

(3) We have seen that PFs are not thises, as the Cat. conceives of thises, but are thises - though not particulars - as the Met. conceives of them. Are ASs thises? They certainly are on the Cat.'s construction; for they are particulars. This, however, is no reason to count ASs as substances, since (3) so construed is not a plausible necessary or sufficient condition for substance.

Are ASs thises on the Met.'s understanding of that notion? So Aristotle claims (1030a3ff.), and I am not concerned to dispute the point. Though many individual forms are predicated of some matter, they are not what they are in virtue of being so predicated - in contrast to compounds, or to such accidental unities as a white man: here no doubt is one reason for opting for individual forms over compounds as the particulars that count as primary substances. And it is also, as we have seen, a 
reason for preferring them to universals since, in Aristotle's view, universals are necessarily predicated of many things.

Notice, though, that the fact that ASs are thises does not render them vulnerable to the TMA, as Aristotle urged PFs would be, if they were thises - for ASs are only particulars, and not also universals. Here is another reason to believe that Aristotle acknowledges individual forms; for the forms that are thises (and so primary substances) cannot be universals, on pain of the TMA.

ASs, then, do better on (1-2), and on (3) construed in terms of particularity, than do PFs. The best Platonic defense in the face of this fact - and I have argued that it is a good one - is to argue that (1-2), and (3) so construed, are not plausible necessary conditions on substance, so that ASs' success over PFs does not impugn PFs'status as substances. On the other hand, insofar as at least (1-2) are plausible sufficient conditions, Aristotle can fairly insist that PFs are not the only substances; ASs qualify as well. This is, to be sure, a more hospitable conclusion than Aristotle wishes to endorse; but it nonetheless involves a significant criticism of Plato, for whom PFs appear to exhaust the ranks of substance.

What, now, of (4-6)? I shall suggest that PFs satisfy (4-6) at least as well as, perhaps better than, ASs - as Aristotle himself should (in some moods) agree (at least in the case of (5-6)). Of course, this gives us no reason to prefer PFs to ASs, unless (4-6) are plausible criteria for substance; so that too needs to be investigated.

(4) In the Cat., Aristotle wisely does not insist that his primary substances are separate, though he less wisely insists that no universals are - less wisely because, as we have seen, universals may well enjoy the capacity for independent existence. In the Met., Aristotle retains his belief that universals are not separate; but he now insists that substance is separate. This insistence, however; is not clearly justified.

Consider compounds first - say Socrates, considered as a compound of form and matter. Socrates, on Aristotle's view, cannot exist and fail to be a man. But then, the secondary substance or species man must exist if Socrates does. (This is so even in the Met., where man no longer counts as a secondary substance.) But if Socrates cannot exist unless man does, he is not independent of, and so is not separate from, man. Similar remarks apply in other cases. For example, although Socrates can of course exist even if he is not tan, he cannot exist if he is not colored in some way; hence he is not independent of color or, therefore, of nonsubstance generally. Nor are individual forms separate. Just as the compound Socrates cannot exist unless man does, so no individual form of man can exist unless man (the universal, however conceived) does. PFs, however, are separate from particulars; and so they, but not ASs, satisfy (4). ${ }^{26}$

One might argue that this is no reason to prefer PFs to ASs, since (4) is not a plausible condition on substance. All that is plausible is the weaker claim of ontological basicness, that the basic entities in the universe be such that other things 
depend on them. (This claim is weaker because it allows mutual dependence.)

This is a reasonable claim: separation may be sufficient for basicness; but it does not seem to be necessary. It does seem reasonable, however, to suppose that basicness involves other entities being dependent on the basic ones; indeed, this seems constitutive of ontological basicness.

Weakening (4) in this way turns it into a plausible condition on substance. But does this help Aristotle? notice first that Plato would of course argue that PFs satisfy not only (4) but also the weaker claim of ontological basicness; sensibles depend on PFs. ${ }^{27}$ But do ASs also satisfy our new version of (4)? Can Aristotle plausibly argue that they are ontologically basic? If, as I have suggested, universals are separate, then of course they are not dependent on ASs, and so ASs are not ontologically basic with respect to them. But if other sorts of things are dependent on ASs, ASs might nonetheless count as ontologically basic. One might argue, for example, that individual nonsubstances (Callias' whiteness, as opposed to the universal, whiteness) or events depend on ASs; if so, ASs are ontologically basic at least in that some other sorts of things depend on them. This is, however, a weaker version of ontological basicness than Aristotle himself defends for ASs in the Cat. (2b3-6), where he claims that all (and not just some) other sorts of things depend on ASs. Still, this weaker version of ontological basicness gives a reasonable sense to the notion, and allows ASs to satisfy it. Hence both PFs and ASs can be allowed to satisfy the new version of (4).

Aristotle himself seems to see the need to modify (4) - though not in the way I have suggested, in terms of ontological basicness. In H.1 (1042a28-31), he distinguishes between being separate without qualification (haplos) and being separate in definition $(\log \bar{o}(\mathrm{i}))$. He claims that although compounds are separate without qualification - that is, can exist without other things - some forms are only separate in definition - that is, can be defined without reference to other things. It is now apparently sufficient for satisfying (4), then, that something be separate in definition.

This suggestion, however, involves at least four difficulties. First, Aristotle in effect concedes that some of his own substances do not satisfy (4), but at best a weakened or modified version of it. To be sure, we earlier urged, on Plato's behalf, that Aristotle's criteria (1-3) are plausible only if modified or weakened. But this involved Plato rejecting Aristotle's criteria; whereas now Aristotle is rejecting his own criteria.

Second, Aristotle still insists that compounds are separate without qualification; but that seems false.

Third, if to define other things one needs to include a definition of substance, then the modified version of (4) collapses into (5); but as we shall shortly see, it is unclear that Aristotle's primary substances satisfy (5). If this is so, then the retreat from (4) to (5) is of no help.

Fourth, the retreat threatens to undermine one of Aristotle's criticisms of Plato. 
We saw before that Aristotle argued that PFs cannot satisfy all of (4-6) without incoherence - for (4) requires particularity, whereas (5-6) require universality. Yet if Aristotle now collapses (4) into (5), he can no longer argue that joint satisfaction of (4) and (5) is incoherent; for to satisfy (5), now, just is to satisfy (4). (To this, I suppose Aristotle could reply that although satisfaction of (5) is sufficient for satisfying (4), PFs are in fact separate without qualification, so incoherence still threatens. But we have seen that Plato has an effective reply to this argument.)

PFs, then, fare better on (4) than ASs do. If, however, (4) is altered to a weak version of ontological basicness - which yields a more plausible condition than (4) then PFs and ASs both satisfy it. Aristotle, however, apparently modifies (4), not in terms of ontological basicness, but in terms of being separate in definition. Let us see, then, how well ASs fare on (5), and its close companion (6).

(5-6) Aristotle begins Met. M.10 by raising a dilemma that, he says, threatens both himself and the Platonist: substances must be separate; whatever is separate is a particular; particulars are unknowable; but substances must be knowable. This is just the dilemma we earlier saw Aristotle force on Plato (IV (5-6)); now he acknowledges that he faces it as well. How does he avoid the dilemma? And does he do so in such a way as to leave intact his criticism of Plato?

Aristotle's solution is to insist that substances must be separate, and so particulars; ${ }^{28}$ but he insists that particulars - or at least some particulars - are knowable after all. Hence Aristotle, like Plato, rejects $(a)$ of the dilemma (see IV (5-6)); but he rejects it by insisting that particulars can be known and defined, whereas Plato rejects it by insisting that universals are separate, but not thereby particulars. We have seen that Plato's response is effective; is Aristotle's?

$\mathrm{He}$ distinguishes between actual and potential knowledge; he then claims that actual knowledge, being definite (horismenon), is of something definite - a particular; whereas potential knowledge being universal and indefinite, is of what is universal and indefinite, or indefinable (ahoriston, 1087a17). One sees color coincidentally, by seeing this token color; or studies the letter A by studying a particular token of the letter-type A.

Aristotle is claiming at least that one can recognize individual objects as tokens of types, or as instances of universals. If this were all he were arguing, one might protest that this recognitive ability is not sufficient to make particulars prior in knowledge or definition; indeed, it is not even sufficient to make them knowable or definable, as Aristotle normally understands those notions. But Aristotle seems to go further, and to insist that particulars are definite or definable, universals indefinite or indefinable (1087a 16-18). This stronger claim allows particulars to be knowable and definable; but it is inconsistent with other claims Aristotle makes, such as the claim in Z. 15, that particulars are indefinable. The claim in M.10 thus seems to be either too weak, or else to contradict other central Aristotelian claims.

Even if this could be resolved, is there a point against the Platonist here? Has Aristotle argued that his own substances satisfy (5-6), but that PFs cannot? If we 
focus on the weak point about recognition, then perhaps Aristotle would argue as follows: we can come to know various universals, or acquire general concepts, only by first learning to recognize and identify various particulars. But these must be this-world particulars, such as compounds and their forms, and not other-worldly particulars, such as PFs. Hence forms and compounds are prior in learning and recognition, whereas PFs cannot be.

In reply, I think Plato would appeal to his doctrine of Anamnesis, and argue that PFs are prior in learning; we can identify objects in this world only because we knew PFs in another world. Aristotle seems to believe that there are two neatly separable stages in learning, as though one first identifies particulars, and only later acquires general concepts.

Though I think Aristotle is right to attack parts of the doctrine of Anamnesis, as he does, for example, in the $A n$. Po., Plato at least sees that we do not first identify particulars, and only later apply general concepts to them; to identify anything, one must already possess general concepts. That is the core of truth in the doctrine of Anamnesis that Aristotle's simple account of concept acquisition ignores. ${ }^{29}$

To learn about properties, however, it is not clear that we need first, or as well, to have access to sensible particulars. Certainly, as even Hume agrees, we can form the idea of a shade of blue we have never seen; so we can at least form ideas of properties independently of particulars that instantiate those very properties. ${ }^{30}$ But perhaps, as Leibniz may believe, we need experience of some particulars to become aware even of our innate ideas. ${ }^{31}$ If so, perhaps the best conclusion to draw, in the case of learning and recognition, is the hospitable one we have suggested in other cases: neither sensible particulars nor PFs (universals) are prior to the other; both are necessary to learning and recognition, to the way we view the world.

What if we turn, then, to scientific-knowledge and definition? If we explicate these notions in Aristotle's usual way, such that there is scientific-knowledge and definition only of universals, then PFs, but not ASs, satisfy (5-6); for PFs, but not ASs, are universals.

One might again argue that this is no reason to prefer PFs to ASs, since (5-6) so construed are at best plausible sufficient conditions for substance. That may well be true, and I shall shortly consider various modifications of (5-6). But notice first that there is a difficulty in Aristotle's pressing this argument; for it involves conceding that his substances do not satisfy his own criteria but, at best, modified versions of them.

Still, how might (5-6) be modified so as to yield more plausible criteria? One might argue that the best sort of knowledge and definition must at least concern permanent features of the universe. From this point of view, PFs, being eternal or everlasting, are better off than many Aristotelian forms, which are perishable. But perhaps Aristotle could insist that at least the prime mover, or god, or the stars, fare as well as do PFs; for they too are imperishable.

One might argue that (5-6) are still too strong to be reasonable criteria for 
substance. Surely the best sort of knowledge and definition will refer, not just to universals or to permanent features of the universe, but also to various sublunar phenomena, not all of which are permanent. After all, we are concerned to understand the world around us, and hence definitions and knowledge must be about it; otherwise we just have an arid deductive system that does not constitute genuine knowledge. If we weaken (5-6) in this way, then it constitutes a plausible criterion for substance; but it is then also one both PFs and ASs satisfy.

PFs and ASs, then, fare equally well on (5-6), if they are construed in terms of learning and recognition. If (5-6) are instead interpreted in terms of scientificknowledge and definition, then PFs fare better than do ASs - unless Aristotle significantly weakens his usual views about the nature of scientific-knowledge and definition. Such modification might yield a more plausible conception of such knowledge and definition; but it is noteworthy that it is required, not to argue against Plato, but to allow his own candidates to satisfy (5-6). In any case, none of the interpretations of (5-6) that we have considered favors ASs over PFs.

It is worth noting, however, that Aristotle's new focus on (5-6) is probably one reason for his advocacy of individual form. First, forms are identical to their essences, as primary substances must now be. Second, though individual forms, being particulars, may not be strictly scientifically-knowable or definable, they are closer to being knowable and definable than are such particulars as compounds. At least, since they do not include matter as compounds do, they are 'purer' instances of universal laws, and so subject to fewer vagaries. This goes along with a point noted before (V (3)): that individual forms, in the $\mathbf{M e t}$., are better thises than are compounds; for they are not what they are in virtue of one thing's being predicated of another, and so are more determinate objects of secure reference.

And it is worth noting too that although Aristotle may not easily be able to defend his claim that individual forms satisfy (5-6), he does try to argue this; he does not, at this point, slide back to the Cat.'s view according to which universals better satisfy (5-6). (5-6) may indeed raise difficulties for Aristotle; but he does not attempt to resolve them by turning to universal substances.

\section{Conclusion}

What can we say, by way of conclusion, about the debate between Plato and Aristotle on what the substances are?

In the Met., Aristotle argues that PFs cannot be substances, because they satisfy none of (2-6) - at least, they satisfy none of them nonproblematically: no universal can be a subject or a this; none can be separate; none is the essence of any particular; none is prior in knowledge or definition. Though Plato would of course protest against most of these claims, Aristotle believes the protest is implausible and, in some cases, that it leads to incoherence, making PFs both universals and particulars at once. ASs, on the other hand, nonproblematically satisfy (2-6), and 
so are the substances. As we have seen, the details of his argument require that his (primary) substances be individual forms.

If our argument has been correct, a different verdict should be returned. Though PFs are not subjects or (Cat.) thises, this does not impugn their status as substances, since these are not plausible necessary conditions on substance; and PFs do satisfy associed weaker, and more plausible, conditions. On the other hand, PFs satisfy (4-6) (in Plato's view; but also, he appears to have a reasonable view here); nor does this require them to be universals and particulars at once. If we focus on (2-6), then, we have been given no reason to reject PFs, and some reason to look on them favorably.

Though Aristotle goes too far in barring PFs from the ranks of substances, he can reasonably press a weaker claim: that ASs belong in the ranks as well. To be sure, ASs satisfy (4-6) only if Aristotle significantly weakens them - a weakening Plato need not countenance. But such weakenings may be welcome, since they yield more plausible criteria for substance than do the initial strong readings. Further, ASs also satisfy (1-2) which, I have conceded to Aristotle, are at least plausible sufficient conditions on substance; and they also satisfy (3), on both of its constructions.

Our argument suggests that we should not accept as legitimate the presupposition of Plato's and Aristotle's question 'What are the substances?' namely, that there is some one sort of entity that has privileged status, or alone satisfies all the criteria for substance. Different sorts of entities - both universals and particulars - are indispensable features of the way the world is, and so of our understanding of the world. ${ }^{32}$

CORNELL UNIVERSITY

BRASENOSE COLLEGE, OXFORD

GAIL FINE

\begin{abstract}
NOTES
1. Some dispute that Forms are, or are only, universals; with Aristotle, I assume that Forms are at least universals. Though all Forms are universals, the converse is not true; Forms appear to be a subclass of universals - non-sensible ones. (I assume that not all universals are nonsensible - redness, e.g., is not.) I discuss some features of Forms in more detail in my 'The One over Many', Philosophical Review 89 (1980) 197-240; and in 'Relational entities', Archiv für Geschichte der Philosophie (1983).

2. I thus align myself with those who believe that in the Met. Aristotle acknowledges individual forms, and counts them as his primary substances. This view is, of course, highly controversial; and my defense of it here is at best partial. That the primary substances of the Met. are individual forms is also defended by E. Hartman, Substance, body, and soul (1977), esp. chapter 2; and W Sellars, 'Aristotle's Metaphysics: an interpretation', in Philosophical perspectives (1959) 73-124. If this view is rejected, then many of the things I say about Aristotle's criticism of, and alternative to, Plato would need to be revised. On the other hand, if I sketch Aristotle's criticisms correctly, that supports the picture I paint of his alternative. I do not deny, by the way, that Aristotle countenances forms (or entities called 'eid $\vec{e}$ ) other
\end{abstract}


than individual forms (see esp. n. 7). But unless otherwise noted, whenever I speak of Aristotelian forms, I shall mean the individual forms that count as primary substances.

3. D. R. Cousin, 'Aristotle's doctrine of substance', Mind, n.s. 42 (1933) 319-37; 43 (1935) 168-85; R. Dancy, Sense and contradiction: a study in Aristotle (1975) $95 \mathrm{ff}$.

4. It is, of course, sometimes disputed that Plato accords sensibles essences or that, if he does, their essences are Forms. For a partial defense of the view assumed here, see 'Relational entities'.

5. Cat. $2 b 7-14 ; 2 b 29-37$. A second reason they count as secondary substances is that they are the second best subjects. I discuss both reasons further below, in III and V.

6. I say 'at best' because not all essences count as secondary substances; only the essences of primary substances do. Redness, or color, are the essences of various nonsubstances; but they are not substances at all.

7. 'eidos' is one word Plato uses for PFs. Aristotle uses 'eidos' in at least the following ways: (a) for individual forms (e.g. Socrates' soul); (b) for species (e.g. man); and (c) for the universal form or essence of that species (e.g. rationality). This multiple usage need not import any confusion. The distinction between $(b)$ and $(c)$ is made much of by J. Driscoll, in 'EIDE in Aristotle's earlier and later theories of substance', in Studies in Aristotle, ed. D. J. O'Meara (1981) 129-159. He argues that in the Met., the primary substances are eide of sort $(c)$; I favor $(a)$. Driscoll is right to argue that $(a)$ is not the only alternative to $(b)$, which he agrees is not primary substance in the $M e t$; ; but there are other reasons for preferring $(a)$ to $(c)$.

8. G.E.L. Owen; 'The Platonism of Aristotle', Proceedings of the British Academy 51 (1965) 125-50, 136-7. In a later article, 'Particular and General' PAS 79 (1978-79), esp. 14-15, however, he seems to have retracted this view in favor of individual forms, though the claim is not pressed.

9. By, e.g., M. J. Woods, 'Substance and essence in Aristotle', PAS 75 (1974-5) 167-80; cf. also C. Kirwan, Aristotle's Metaphysics: Books $\Gamma, \Delta$, and E (1971), esp. 100-101.

10. Cf. J. L. Ackrill, Aristotle's Categories and De Interpretatione (1963) 89-90. The translation is also Ackrill's; all other translations are my own.

11. Thus, in Z.4 (1030a5-6) he says that only substances are thises; and in Z.3, matter is ruled out as (the sole) substance on the grounds that, inter alia, it is not a this $(1029 \mathrm{a} 28-30)$. The notion of a tode $t i$ is difficult, and has been explicated in many different ways. Cf., e.g., J. A. Smith, 'TODE TI in Aristotle', $C R 35$ (1921) 19; Owen, 'Particular and general', 2; J. Barnes, Aristotle (1982), 43. Barnes remarks that tode $t i$ is 'an unorthodox phrase which Aristotle nowhere explains'.

12. I am unsure whether (1) is tacit in the Met. Perhaps it plays a role in the restriction Aristotle sometimes makes of substances to natural substances, i.e. to those with internal sources of change. In any case, I shall largely ignore (1) when speaking of the Met.

13. I take both 'chöris' and 'chöriston', as used in connection with substance and PFs, to indicate actual, and not merely possible, separation; and I take actual separation to be the capacity for independent existence. Most of the claims I make in this paper about separation are defended in detail in 'On the separation of Platonic Forms', forthcoming in Oxford Studies in Ancient Philosophy (1984).

14. At 1028a32-3, I read: kai physei kai logōo(i) kai gnōsei - adding 'physeì' to, and deleting 'chronōo(i)' from, Jaeger's text. This emendation is not essential to my view.

15. I say that in the Cat., Aristotle denies that universals are separate. To be sure, this follows from his remark that universals are ultimately dependent on primary substances; but it is interesting to note that Aristotle does not use 'chöris' or its cognates in pressing this claim. Notice, in this connection, the 
account of natural priority in Cat. 14b10-22. Here, in striking contrast to Met. Z.1, A can be naturally prior to $B$ without being separate from $B$; indeed, separation is actually precluded, since natural priority is defined so as to obtain only between items that reciprocate as to existence. In general, the Cat. has considerably less to say about separation than the Met. does. 'Chöris' and its cognates occur only once, at $1 \mathrm{a} 25$.

16. Such, at any rate, appears to be the implication of Z.1. Even if (5) is only necessary, however (and it is clearly at least that), the problems I raise for Aristotle over (5) would remain (see below, V (5)). One might find it tempting to weaken (5) so that it requires only that ousiai be mentioned (as opposed to defined) in every definition. I know of no place where priority in definition is explicated in this weaker way, however. But even if it is, neither would this remove the difficulties canvassed below; for substance must still be definable, even if its definition need not actually occur in definitions of other things, and that is sufficient for the worries I later air. Analogous remarks to those made in this note apply to (6).

17. Aristotle, of course, believes that Plato intends PFs to be efficient causes of change (Met. $991 \mathrm{b3}-9=1080 \mathrm{a} 2-8$; cf. G.C. 335b7-15, 18-24), and he criticizes them on that score. Aristotle has recently been defended by J. Annas, 'Aristotle on inefficient causes', Philosophical Quarterly (1982) 311-326. But I was unpersuaded by her argument, which seems to assume that if Plato does not explicitly distinguish between efficient and other sorts of causes, he must be confused about their differences. A more sympathetic reading of Plato is provided by G. Vlastos, 'Reasons and causes in the Phaedo', Philosophical Review 78 (1969) 291-325.

18. Owen, 'Particular and general', 2. This is Owen's explication of what Aristotle means by 'subject'. If Owen is right, then PFs are subjects in Aristotle's sense; but I doubt that Owen is right.

19. The issue is disputed; but for one plausible defense of the possibility of uninstantiated universals, see P. Butchvarov, Resemblance and identity (1966) 186-97.

20. See Owen, 'Particular and general', 14; contrast the passage cited above from 'Platonism'.

21. 'Self-predication', as traditionally construed, is the claim that the Form of $F$ is itself an $F$ thing, a member of the class of F things; the Form of Large, e.g., is itself large. If S. Peterson's account of selfpredication is accepted, there would be even less reason to suppose that self-predication implies particularity. See S. Peterson, 'A reasonable self-predication premise for the Third Man Argument', Ph. R. 82 (1973) $451-470$.

22. Indeed, the $\mathrm{Met}$. account of thisness has Platonic antecedents: cf. Crat. 439 $\mathrm{c6}-440 \mathrm{cl}$; Tht. 181-3; So. 261-3; Tm. 48e2-52dl. For some discussion, see D. Zeyl, 'Talk of a world in flux', HSCP79(1975), esp. 146-8; J. Driscoll, 'The Platonic ancestry of primary substance', Phronesis (1979) 253-269. Interestingly, Plato never seems explicitly to say that PFs are thises, so conceived; and like Aristotle he at least sometimes uses similar phrases of sensible particulars. But his notion of being a this is not defined in terms of sensible particulars; and PFs satisfy his notion, even if he does not himself explicitly make the point.

23. See esp. Met. M.9; I discuss the passage in detail in 'Separation'.

24. Aristotle may, however, intend to foreclose this possibility in Met. Z.13.

25. I assume mereological essentialism is false.

26. Notice that this problem for ASs is not alleviated by claiming that they are universals, not particulars; for as we have seen, Aristotle consistently denies that universals are separate, and he consistently associates separation with particularity. On the other hand, T. H. Irwin has suggested to me that ASs - conceived as individual forms - are, contrary to my suggestion, separate, at least from universals: whenever Aristotle defines universals, he defines them in terms of being predicated of many things. Suppose that only Socrates - one man - exists. Then the universal, man, does not exist; its 
existence requires the existence of many men. But if Socrates exists, and the universal, man, does not, then Socrates is separate from man. A parallel argument shows that Socrates is separate from all universals. He is not, of course, independent of, e.g., his individual pallor or height; but perhaps these are not other than him, and so he need not be separate from them. (An analogous argument might be used to show that neither is he separate from his matter; for he is not other than it in the requisite way.) But if Socrates is separate from all universals so, too, is every other man and, analogously, every other AS.

I am unpersuaded by this argument, however. Even if it is accepted, it gives us no reason to prefer ASs to PFs; it shows at most that universals and particulars are on an equal footing.

27. This might actually be disputed. Suppose, as is sometimes believed, that there are Forms only corresponding to the accidental properties of things. Then even if Socrates is, e.g., tan, in virtue of participating in the Form of Tan, he is not dependent on the Form, since he can exist without it; he would of course then cease to be tan, but that would not impugn his continued existence. However, at least in the Timaeus there are Forms corresponding to some of the essential properties of things (there is, e.g., a Form of Man), and so at least there sensibles do depend on (some) Forms: Socrates could not exist if he were not a man; hence he is dependent on the Form of Man, since he can be a man only by participating in it. I discuss this issue more fully in 'Relational entities'.

28. Notice that if separation here is definitional separation (and not IE), then Aristotle apears to believe that even definitional separation implies particularity. And at least one line of thought does yield this result: in Z.1, Aristotle argues that every definition must include a definition of ousia. If all ousiai are substance particulars, then definitions of everything else, including universals, must include definitions of them. But then no universal can be definitionally separate; each must include a definition of a substance particular. Hence if something is definitionally separate, it is a particular. I rather suspect, however, that separation here is IE.

29. This is, of course, a controversial account of Aristotle that I do not have the space to defend here.

30. D. Hume, A treatise of human nature, ed., L. A. Selby-Bigge (1888), Book I, Pt. 1; Enquiry concerning human understanding, ed. L. A. Selby-Bigge (1902), section 2.

31. G. W. Leibniz, New essays on human understanding, translated and edited by P. Remnant and J. Bennett (1981), Book I, chapter 1, passim.

32. An earlier version of this paper was read at the Oxford Philosophical Society in November, 1982; I thank the audience on theat occasion for a number of helpful comments. I especially wish to thank my commentator, Professor J. L. Ackrill, for generous and helpful written and oral comments; and also Terry Irwin, M. M. Mackenzie, and Jennifer Whiting. I am also grateful to the National Endowment for the Humanities for awarding me a fellowship for 1982-3, and to the Principal and Fellows of Brasenose College, Oxford, for electing me to a Visiting Fellowship for 1982-3. 